\title{
Predicting nutrient digestibility in high-producing dairy cows
}

\author{
R. A. de Souza, ${ }^{*}$ R. J. Tempelman, ${ }^{*}$ M. S. Allen, ${ }^{*}$ W. P. Weiss, † J. K. Bernard, $\ddagger$ and M. J. VandeHaar*1 \\ *Department of Animal Science, Michigan State University, East Lansing 48824 \\ †Department of Animal Science, The Ohio State University, Wooster 44691 \\ ‡Department of Animal \& Dairy Science, University of Georgia, Tifton 31793
}

\section{ABSTRACT}

Our objective was to determine the effects of dry matter intake (DMI), body weight (BW), and diet characteristics on total tract digestibilities of dry matter, neutral detergent fiber, and starch (DMD, NDFD, and StarchD, respectively) in high-producing dairy cows. Our database was composed of 1,942 observations from 662 cows in 54 studies from Michigan, Ohio, and Georgia. On average, cows ate $23 \pm 4.5 \mathrm{~kg}$ of dry matter/d, weighed $669 \pm 79 \mathrm{~kg}$, and produced $38 \pm$ $10 \mathrm{~kg}$ of milk/d. Diets were $31 \pm 5 \%$ neutral detergent fiber, $27 \pm 6 \%$ starch, $2.6 \pm 1.2 \%$ fatty acids, and $17 \pm 1.4 \%$ crude protein. Digestibility means were $66 \pm 6,42 \pm 11$, and $93 \pm 5 \%$ for DMD, NDFD, and StarchD, respectively. Forage sources included corn silage, alfalfa, and grasses. Corn source was classified by its ruminal fermentability. Data were analyzed using a mixed effects model, including diet chemical composition, forage source, and corn source, all expressed as percentage of dry matter, except for DMI, which was expressed as percentage of BW (DMI\%BW); location and 2-way interactions were fixed effects. Cow, block, period, treatment, and study were included as random effects. Best fitting candidate models were generated using backward and stepwise regression methods. Additionally, the simplest model was generated using only DMI and location as fixed effects and all random effects. Candidate models were cross-validated across studies, and the resulting predictive correlation coefficients across studies (PC) and root mean square error of prediction (RMSEP) were compared by $t$-test. For each nutrient, the digestibility model that resulted in the highest PC and lowest RMSEP was determined to be the best fitting model. We observed heterogeneous coefficients among the different locations, suggesting that specific location factors influenced digestibilities. The overall location-averaged best fitting prediction equations were: $\mathrm{DMD}=69-0.83 \times \mathrm{DMI} \% \mathrm{BW}(\mathrm{PC}$

Received June 16, 2017.

Accepted September 26, 2017.

${ }^{1}$ Corresponding author: mikevh@msu.edu
$=0.22$, RMSEP $=5.39) ; \mathrm{NDFD}=53+0.26 \times$ grass $\% \mathrm{DM}-0.59 \times$ starch $\% \mathrm{DM}+3.06 \times \mathrm{DMI} \% \mathrm{BW}-$ $0.46 \times \mathrm{DMI}_{0} \mathrm{BW}^{2}(\mathrm{PC}=0.53, \mathrm{RMSEP}=9.70) ;$ and StarchD $=96+0.19 \times$ HFERM\%DM $-0.12 \times$ starch $\% \mathrm{DM}-1.13 \times \mathrm{DMI} \% \mathrm{BW}(\mathrm{PC}=0.34, \mathrm{RMSEP}=$ 4.77); where HFERM\%DM is highly-fermentable corn source as percentage of DM. Our results confirm that digestibility is reduced as DMI increases, albeit at a lower rate than that reported in National Research Council. Furthermore, dietary starch depresses NDFD. Whereas DMD can be predicted based on DMI only, the best predictions for NDFD and StarchD require diet characteristics in addition to DMI.

Key words: model, intake, NDF, starch

\section{INTRODUCTION}

The primary goal of any nutrition program is to formulate diets that meet the nutrient requirements of the animal. To design an effective program, data on both DMI and nutrient digestibility are needed, as a major factor influencing nutrient utilization in dairy cattle is the relationship between intake and digestibility (Colucci et al., 1982). In lactating dairy cows, DMI is driven by milk production but can be limited by physical fill and metabolic effects (Allen, 2000). Increased DMI increases passage rate of digesta and, thus, depresses digestibility of nutrients (Tyrrell and Moe, 1975). However, a clear understanding of animal and dietary factors that influence intake, digestibility, and their interactions is still lacking.

The equation used by the NRC (2001) to estimate digestibility is based on TDN content of the diet at maintenance and intake expressed as a multiple of maintenance. This equation may not adequately describe digestibility of high-producing dairy cows because the equation used by NRC (2001) was based primarily on data derived at lower levels of intake. Moreover, starch content is likely more important than TDN content in determining the digestibility discount (Ferraretto et al., 2013).

Previous meta-analyses have focused on both dietary and animal characteristics to model digestibility in lac- 
tating dairy cows. Huhtanen et al. (2009) summarized the effects of feeding level and diet composition on digestibility. They reported that TDN could be calculated for lactating cows using OM digestibility at a maintenance level determined either in vivo in sheep or by using in vitro methods, DMI, CP content, and proportion of forage in the diet. Nousiainen et al. (2009) analyzed data from lactating cows and determined effects of forage quality, the proportion of concentrate, CP content, and fibrous by-products on OM and NDF digestibility. These findings suggest that inclusion of both dietary and animal factors were critical for accurate modeling of digestibility. However, these meta-analyses included only treatment means of the contributing factors available in the studies summarized and not data from individual cows. In human medical research, meta-analyses are commonly performed using individual observations (Riley et al., 2010), but this is not common in animal science. Riley et al. (2010) summarized the benefits of using individual observation data over treatment means data; contextualizing the advantages cited by Riley et al. (2010) to the current study, when treatment means are used the ability to quantify variability among animals within the same diet is reduced such that important information about the effect of DMI on digestibility is lost.

The objective of our study was to develop equations to estimate total tract digestibility of DM (DMD), NDF (NDFD), and starch (StarchD) using recent data derived from individual observations of highproducing lactating cows. We hypothesized that diet, especially dietary starch, and animal characteristics, specifically DM as a percentage of BW, together would provide accurate predictions of nutrient digestibility.

\section{MATERIALS AND METHODS}

Our analysis was based on individual observations of lactating Holstein dairy cows from 54 studies, 85\% of which were conducted in the last $15 \mathrm{yr}$; a few of which have not yet been published. A complete list of the sources of these studies is provided in the Supplementary Material (https://doi.org/10.3168/jds.2017 -13344). These studies were conducted at Michigan State University (MSU), The Ohio State University, and the University of Georgia. The final database contained 1,942 observations from 662 cows on 195 different treatments.

The variables included in the database were DMD, NDFD, StarchD, BW, metabolic BW (MBW, $\mathrm{kg}^{0.75}$ ), milk yield (MY), DMI, dietary ingredients, and dietary chemical composition (Table 1). Additional information on studies included experimental design and treatment arrangement.
Among the 54 studies, the methods for total-tract digestibilities determination included total fecal collection ( $\mathrm{n}=16$ studies at Ohio State University; Weiss and Shockey, 1991), the use of chromic oxide as an external marker ( $\mathrm{n}=12$ studies at MSU; Voelker and Allen, 2003), and the use of indigestible NDF ( $n=19$ studies at MSU; Cochran et al., 1986) and indigestible ADF ( $\mathrm{n}=7$ studies at University of Georgia; Cochran et al., 1986) as internal markers. Feed fractions used in the analysis included NDF, nonforage NDF (nfNDF), forage NDF (fNDF), starch, total fatty acids (FA), and $\mathrm{CP}$, all expressed as a percent of DM. Values for these fractions were used as reported in the original paper, using standard methods. When neither nfNDF nor fNDF was reported in a publication, the nfNDF was estimated based on the concentrate composition using values from NRC (2001) and fNDF was determined by subtracting nfNDF from NDF. When the FA concentration was not reported, it was estimated based on ether extract [using FA = ether extract -1 , NRC (2001)] or on diet composition. The descriptions of ingredients and chemical composition of the diets are presented in Table 1.

The forage sources in these studies were mainly corn silage, alfalfa hay and silage, wheat straw, orchardgrass silage, and ryegrass silage. The diets contained different amounts of each forage source in various combinations. Forages were categorized as corn silage (CS\%DM; inclusion of corn silage in the diet, expressed as a percent of DM), grass (Grass\%DM; inclusion of wheat straw, orchardgrass silage, and ryegrass silage in the diet, expressed as a percent of DM), and alfalfa (Alfalfa\%DM; inclusion of alfalfa hay and silage in the diet, expressed as a percent of DM). Grass and alfalfa were classified by maturity as immature (grass: $<55 \% \mathrm{NDF}$; alfalfa: $<40 \%$ NDF), mid-mature (grass: 55-60\% NDF; alfalfa: 40-46\% NDF), and mature (grass: $>60 \%$ NDF; alfalfa: $>46 \% \mathrm{NDF}$ ). The only exception for this classification was that wheat straw, in the Grass\%DM category, was classified as mature independent of its NDF content. Whereas NDF content is not a perfect predictor of maturity, it was the best predictor of maturity reported in all the studies used in our analysis. Additionally, the forages were grouped according to their type: silage or hay. Nonforage fiber sources (NFFS) included alfalfa meal, beet pulp, soy hulls, wheat middlings, whole cottonseed, brewers wet grain, and distillers grain; they were all grouped as NFFS (inclusion of NFFS in the diet, expressed as s percent of DM).

Regarding the concentrate ingredients, corn was categorized according to the ruminal fermentability of the source, such that high-moisture corn and steamflaked corn were classified as highly fermentable (HFERM\%DM; inclusion of highly fermentable corn 


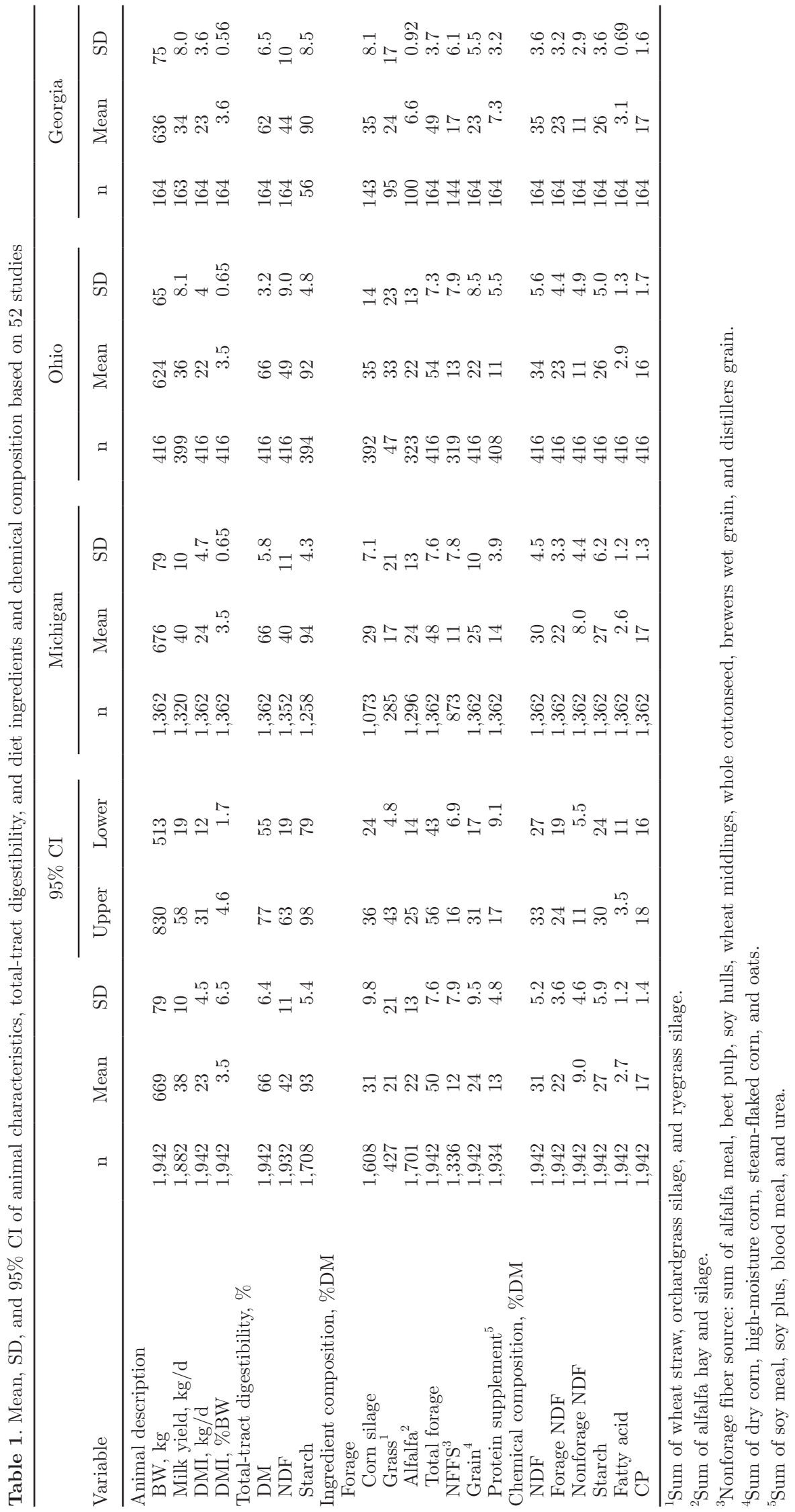


in the diet, expressed as a percent of DM) and ground dry corn was classified as moderately fermentable (MFERM\%DM; inclusion of moderately fermentable corn in the diet, expressed as a percent of DM).

All statistical analyses were performed using SAS v. 9.4 (SAS Institute Inc., Cary, NC). For numerical stability, all covariates $(\mathrm{X})$ were rescaled according to Kutner et al. (2005) using the formula: $\mathrm{X}^{*}=[\mathrm{X}-$ midpoint $(\mathrm{X})] /[0.5 \times$ range $(\mathrm{X})]$.

All covariates were jointly checked for multicollinearity and Pearson correlations between the covariates were computed. When covariates were highly correlated or had variance inflation factors (VIF) greater than 10 (multicollinearity analysis), the covariate with lesser interest was removed from the analysis. For example, if the MY and DMI had VIF greater than 10 the MY was removed because our focus was on DMI. This process was performed until all covariates in the model have VIF lower than 10. Subsequently, the full models containing the linear, quadratic, and cubic effects of all dietary variables, DMI, location, all possible 2 -way interactions between dietary variables, DMI, and location, cow, block, period, treatment, and study were created. The generic full model was

$$
\begin{aligned}
Y_{\text {lcbpts }}= & \beta_{0}+\sum_{d=1}^{8} \alpha_{d} \times \text { Diet }_{d}+\sum_{d=1}^{8} \gamma_{d} \times \text { Diet }_{d}^{2}+\sum_{d=1}^{8} \delta_{d} \times \text { Diet }_{d}^{3}+ \\
& \beta_{1} \times \text { Intake }+\beta_{2} \times \text { Intake }^{2}+\beta_{3} \times \text { Intake }^{3}+\theta_{l} \times \text { Location }_{l}+ \\
& \sum_{d=1}^{8} \epsilon_{d} \times \text { Diet }_{d} \times \text { Intake }_{i}+\sum_{d=1}^{8} \theta_{d l} \times \text { Diet }_{d} \times \text { Location }_{l}+ \\
& \rho_{l} \times \text { Intake } \times \text { Location }_{l}+\text { Cow }_{c}+\text { Block }_{b}+\text { Period }_{p}+ \\
& \text { Treatment }_{t}+\text { Study }_{s}+\varepsilon_{\text {lcbpts }},
\end{aligned}
$$

where $Y_{\text {lcbpts }}$ is the nutrient digestibility (DMD, NDFD, or StarchD); $\beta_{0}$ is the intercept; Diet $_{d}$ are the diet covariates $[d=$ Grass\%DM, Alfalfa\%DM, CS\%DM, HFERM\%DM, MFERM\%DM, NDF (\%DM), starch $(\% \mathrm{DM}), \mathrm{FA}(\% \mathrm{DM})$, and $\mathrm{CP}(\% \mathrm{DM})]$, all expressed as percent of DM; $\alpha_{d}$ are the linear coefficients for the Diet $_{d} ; \gamma_{d}$ are the quadratic coefficients for the Diet $_{d} ; \delta_{d}$ are the cubic coefficients for the Diet $_{d} ; \beta_{1}, \beta_{2}$, and $\beta_{3}$ are the linear, quadratic, and cubic coefficients for the intake; $\epsilon_{d}$ is the coefficient for the interaction between Diet $_{d}$ and intake; Location $_{l}$ is the effect of location $l$ ( $l=$ Michigan, Ohio, and Georgia); $\theta_{d l}$ is the linear coefficient on Diet $_{d}$ for Location . All other terms were random effects, including $C_{0} w_{c}$ for cow $c$ ( $c=1$ to 662), $B_{\text {Bock }}$ for block $b$ ( $b=1$ to 94 , referring to the original design structure of the study), Period $_{p}$ for period $p$ ( $p=$ 1 to 135), and Treatment $t_{t}$ for treatment $t(t=1$ to 195) all nested within studies, Study for study $s(s=1$ to $52)$, with $\varepsilon_{\text {lcbpts }}$ being the error term.
For each response variable (DMD, NDFD, and StarchD), 4 full models were used based on 4 different options for modeling DMI as a covariate: (1) with DMI as percent of BW (DMI\%BW), (2) with DMI as percent of MBW, (3) with DMI as kilograms per day and BW also modeled as a covariate, and (4) with DMI as kilograms per day and MBW also modeled as a covariate. Data points with Studentized residuals greater than \pm 3.5 were considered outliers and removed from the analysis.

The process of choosing a final working model included 2 different model selection methods and was divided into 3 phases. In the first phase, each of the full models was subjected to a backward or a forward stepwise model selection method using the SAS procedure GLMSELECT; this phase yielded 2 reduced models, one using a backward selection method (backward method) and the other using a forward or stepwise selection method (stepwise method). Because the GLMSELECT procedure does not allow random effects, the model containing only the fixed effects described earlier was used in this first phase. In the second phase, each 1 of the 2 reduced models generated by the GLMSELECT procedure was analyzed using the HPMIXED procedure, which included the random effects described in the full model. The variables with highest $P$-values were successively removed until only significant variables $(P<0.05)$ remained in the model. As a result, this phase yielded 2 candidate models. At this juncture, we modeled potential heterogeneous residual variances among the various marker techniques nested within location, recognizing that measurement error could vary substantially among these various techniques. Additionally, we created a third candidate model, which was the simplest model, containing only the linear, quadratic, and cubic partial regressions on DMI, location, and the random effects; in other words, this simple model included no feed factors. In summary, 12 reduced models for each nutrient digestibility were generated [4 models with different covariate specifications for $\mathrm{DMI}$ and $\mathrm{BW} \times(2$ selection methods +1 simplest model $)=12$ reduced models].

Finally, in the third phase, the candidate models (i.e., chosen by backward versus stepwise method and the simplest model including no feed factors) were further compared based on cross-validation. In cross-validation, the entire data set was repeatedly partitioned into a training data set and a test data set. Parameters estimated from the training data set using the candidate model were then used to predict responses in the test data set. The key performance metric is the correlation between predicted and actual responses in the test data set; we referred to this correlation as the predictive cor- 
relation (PC). Furthermore, we calculated the following fit statistics metrics: concordance correlation coefficient (CCC), mean bias, slope bias, mean square error of prediction (MSEP), the decomposition of MSEP into mean bias, slope bias, and random errors (expressed as percentage of MSEP; Tedeschi, 2006), and the root mean square error of prediction (RMSEP). We conducted a 5-fold cross-validation, whereby the data were partitioned into 5 components, with each component taking a turn as the test data set and the remaining 4 components being training data. Test data sets were constructed to contain entire studies; that is, each test data set was constructed to contain all the data from roughly $20 \%$ of the studies. This strategy was chosen to select models that best robustly predicted responses across separate studies. We conducted this 5-fold crossvalidation 20 different times for a total of 100 replicates. The fit statistic parameters from different models were formally compared using a paired $t$-test, blocking on the test data set. If the models did not differ in their mean PC $(P>0.05)$, the second criteria adopted was the model with smaller RMSEP, and third criteria adopted was the model with higher CCC. Because the best fitting equations expressed DMI\%BW, only the models generated with this method of expressing intake are presented in this study.

\section{RESULTS}

In the first step of the statistical analysis (assessing multicollinearity and simple correlation), the variables MY, NFFS, forage maturity (immature, mid-maturity, or mature), forage type (hay or silage), and NDF were removed because they were highly correlated $(P<0.05)$ with other variables of greater interest. For example, MY was removed to keep DMI in the model and NDF was removed to keep nfNDF and fNDF in the model. The candidate models for DMD, NDFD, and StarchD are presented in Tables 2, 3, and 4, respectively.

\section{DMD}

For the DMD equations (Table 2), both selection methods (backward and stepwise) produced similar equations containing the linear effect of HFERM\%DM, linear and quadratic effects of nfNDF, the linear effect of DMI\%BW, the effect of location, and the interaction between location and dietary factors. Additionally, the

Table 2. Estimated partial regressions coefficients $( \pm \mathrm{SE})$ of DM digestibility

\begin{tabular}{|c|c|c|c|}
\hline Effect & $\mathrm{BS}_{\text {model }}{ }^{1}$ & SS model ${ }^{2}$ & Simplest model $^{3}$ \\
\hline Intercept $^{4}$ & $64.4 \pm 1.9$ & $67.7 \pm 1.53$ & $68.7 \pm 0.83$ \\
\hline Highly fermentable starch source & $0.00742 \pm 0.0199$ & $0.014 \pm 0.020$ & - \\
\hline nfNDF $(\operatorname{lin})^{5}$ & $0.70 \pm 0.25$ & $0.27 \pm 0.21$ & - \\
\hline nfNDF (quad) $)^{5}$ & $-0.0018 \pm 0.0078$ & $-0.016 \pm 0.0078$ & - \\
\hline Intake $^{6}$ & $0.036 \pm 0.039$ & $-0.87 \pm 0.25$ & $-0.83 \pm 0.20$ \\
\hline nfNDF $\times$ Intake & $-0.10 \pm 0.035$ & - & - \\
\hline Observations $^{7}$ & 1,874 & 1,874 & 1.874 \\
\hline $\mathrm{PC}^{8}$ & $0.19^{\mathrm{b}}$ & $0.24^{\mathrm{a}}$ & $0.22^{\mathrm{ab}}$ \\
\hline $\mathrm{CCC}^{9}$ & $0.17^{\mathrm{a}}$ & $0.18^{\mathrm{a}}$ & $0.17^{\mathrm{a}}$ \\
\hline Mean bias & $-0.37^{\mathrm{a}}$ & $-0.47^{\mathrm{a}}$ & $-0.41^{\mathrm{a}}$ \\
\hline Slope bias & $-0.47^{\mathrm{b}}$ & $-0.43^{\mathrm{b}}$ & $0.33^{\mathrm{a}}$ \\
\hline $\operatorname{MSEP}^{10}$ & $29.95^{\mathrm{a}}$ & $27.70^{\mathrm{a}}$ & $29.68^{\mathrm{a}}$ \\
\hline \multicolumn{4}{|l|}{ Decomposition of MSEP, $\%$ of MSEP } \\
\hline Mean bias & $6.53^{\mathrm{a}}$ & $6.12^{\mathrm{a}}$ & $7.73^{\mathrm{a}}$ \\
\hline Slope bias & $8.43^{\mathrm{a}}$ & $4.67^{\mathrm{b}}$ & $6.91^{\mathrm{a}}$ \\
\hline Random error & $85.04^{\mathrm{b}}$ & $89.21^{\mathrm{a}}$ & $85.36^{\mathrm{b}}$ \\
\hline $\mathrm{RMSEP}^{11}$ & $5.42^{\mathrm{a}}$ & $5.20^{\mathrm{a}}$ & $5.39^{\mathrm{a}}$ \\
\hline
\end{tabular}

a,b Means within a row with different superscripts differ $(P<0.05)$.

${ }^{1}$ Reduced model generated by backward method.

${ }^{2}$ Reduced model generated by stepwise method.

${ }^{3}$ Simplest reduced model.

${ }^{4}$ Intercept contains the effect of location (Michigan, Ohio, and Georgia) weighted by the number of studies from each location.

${ }^{5}$ Linear and quadratic term for nonforage NDF (\%DM).

${ }^{6}$ Linear term of intake (DMI, \%BW).

${ }^{7}$ Number of observations used to generate the equation.

${ }^{8}$ Predictive correlation.

${ }^{9}$ Concordance correlation coefficient.

${ }^{10}$ Mean squared error of prediction.

${ }^{11}$ Root of mean squared error of prediction. 
Table 3. Estimated partial regressions coefficients $( \pm \mathrm{SE})$ of NDF digestibility

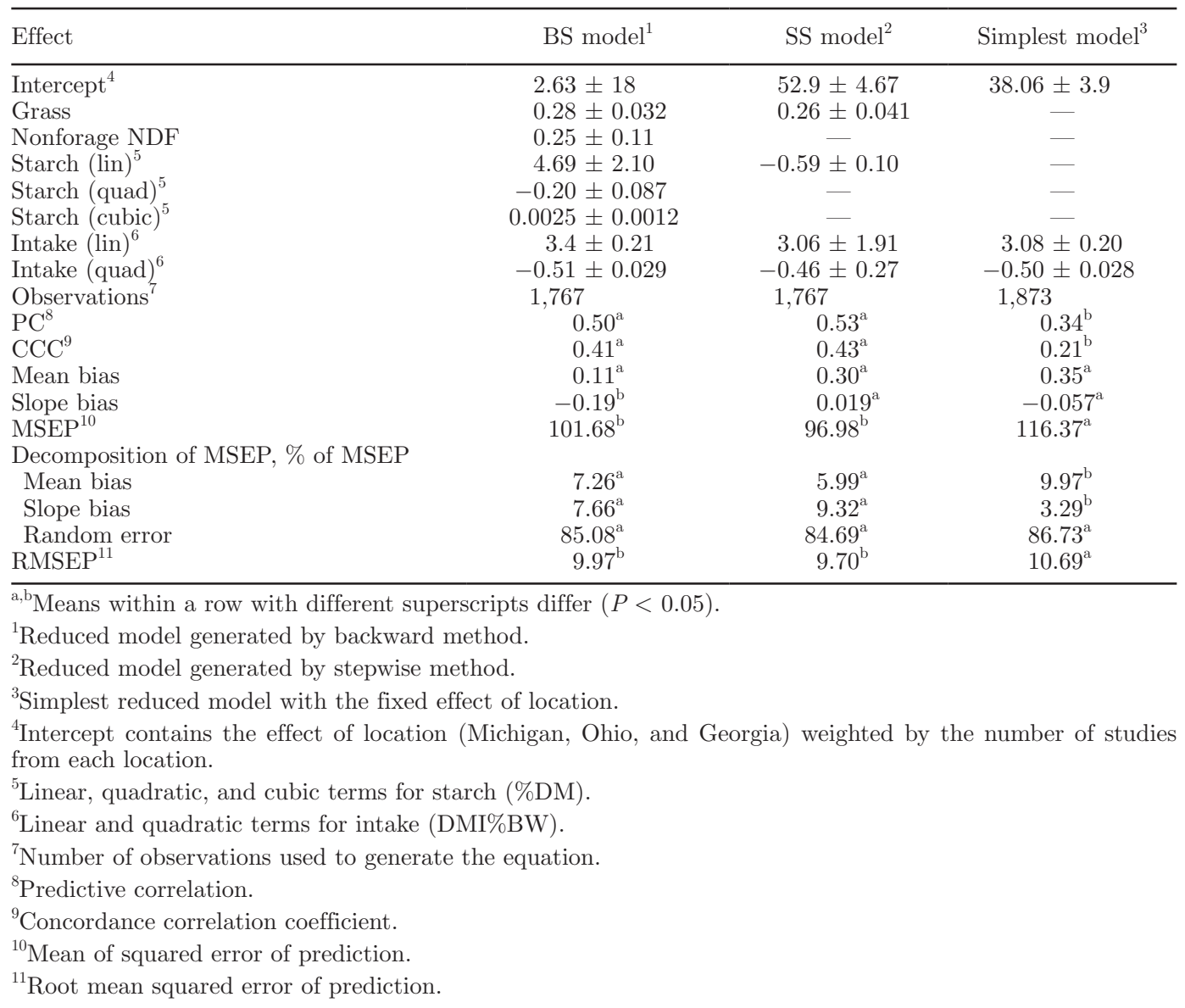

model chosen using backward method contained the interaction between nfNDF and DMI\%BW. When the 3 candidate models were compared by cross-validation across studies they were not found to be different, so the chosen equation was the simplest model (Equation $[1], \mathrm{PC}=0.22, \mathrm{RMSEP}=5.39, \mathrm{CCC}=0.17)$ :

$$
\mathrm{DMD}=69-0.83 \times \mathrm{DMI} \% \mathrm{BW}
$$

where the estimated overall intercept (69) and estimated overall partial regression coefficient $(-0.83)$ on $\mathrm{DMI} \% \mathrm{BW}$ were weighted by the number of studies from each location. Estimates for the intercept and partial regression coefficient on DMI\%BW for Michigan, Ohio, and Georgia were 68 and $-0.59,67$ and -0.18 , and 74 and -3.22 , respectively, as shown in Supplemental Table S1 (https://doi.org/10.3168/jds.2017-13344).

\section{NDFD}

To predict NDFD (Table 3), the backward selection method produced a candidate model that contained the linear effect of Grass\%DM and nfNDF, linear, quadratic, and cubic effect of starch, the linear and quadratic effects of DMI\%BW, the effect of location, and interactions between location and dietary factors. The stepwise method produced a candidate model that included the linear effects of Grass\%DM and starch, the linear and quadratic effects of DMI\%BW, the effect of location, and interactions between location and dietary factors. When the 3 candidate models were compared by cross-validation across studies, the candidate model chosen by the stepwise method had highest PC with the fewest number of terms (Equation [2], $\mathrm{PC}=0.53$, $\mathrm{RMSEP}=9.70, \mathrm{CCC}=0.43)$ :

$$
\begin{gathered}
\mathrm{NDFD}=53+0.26 \times \text { Grass } \% \mathrm{DM}-0.59 \times \mathrm{S} \% \mathrm{DM} \\
+3.06 \times \mathrm{DMI} \% \mathrm{BW}-0.46 \times \mathrm{DMI}^{2} \mathrm{BW}^{2},
\end{gathered}
$$

where the estimated overall intercept (53), and the overall partial regression coefficients on Grass\%DM (0.26) and starch expressed as a percentage of DM (Starch\%DM; - 0.59) were weighted by the number of studies from each location. Estimates for the intercept 
Table 4. Estimated partial regressions coefficients $( \pm \mathrm{SE})$ of starch digestibility

\begin{tabular}{|c|c|c|}
\hline Effect & $\mathrm{BS}$ model $^{1}$ & $\mathrm{SS}$ model $^{2}$ \\
\hline $\begin{array}{l}\text { Intercept }^{3} \\
\text { Highly fermentable starch source } \\
\text { Starch } \\
\text { Intake }^{4} \\
\text { Observations }^{5} \\
\text { PC }^{6} \\
\text { CCC }^{7} \\
\text { Mean bias } \\
\text { Slope bias } \\
\text { MSEP } \\
\text { Decomposition of MSEP, } \\
\text { \% of MSEP } \\
\text { Mean bias } \\
\text { Slope bias } \\
\text { Random error } \\
\text { RMSEP }\end{array}$ & $\begin{array}{c}96.3 \pm 1.88 \\
0.19 \pm 0.055 \\
-0.12 \pm 0.078 \\
-1.13 \pm 0.14 \\
1,649 \\
0.34^{\mathrm{a}} \\
0.29^{\mathrm{a}} \\
0.09^{\mathrm{a}} \\
0.11^{\mathrm{a}} \\
24.47^{\mathrm{a}}\end{array}$ & $\begin{array}{c}95.4 \pm 0.7 \\
- \\
-1.03 \pm 0.19 \\
1,649 \\
0.27^{\mathrm{b}} \\
0.26^{\mathrm{b}} \\
0.14^{\mathrm{a}} \\
0.25^{\mathrm{a}} \\
25.01^{\mathrm{a}}\end{array}$ \\
\hline $\begin{array}{l}\text { a,b Means within a row with differe } \\
{ }^{1} \text { Reduced model generated by bac } \\
{ }^{2} \text { Simplest reduced model with the } \\
{ }^{3} \text { Intercept contains the effect of loc } \\
\text { weighted by the number of studie } \\
{ }^{4} \text { Intake expressed as percent of B } \\
{ }^{5} \text { Number of observations used to } \\
{ }^{6} \text { Predictive correlation. } \\
{ }^{7} \text { Concordance correlation coefficie } \\
{ }^{8} \text { Mean squared error of prediction }\end{array}$ & $\begin{array}{l}\text { kward selection. } \\
\text { fixed effect of lo } \\
\text { ation (Michigan, } \\
\text { from each locat } \\
N \text { (DMI, \%BW). } \\
\text { senerate the equa }\end{array}$ & $\begin{array}{l}\text { ( }(P<0.05) \text {. } \\
\text { ion. } \\
\text { iio, and Georgia } \\
\text { n. }\end{array}$ \\
\hline
\end{tabular}

and partial regressions coefficient on Grass\%DM and Starch\%DM for Michigan, Ohio, and Georgia were 50, 0.38 , and $-0.60 ; 45,0.26$, and -0.11 ; and $85,-0.21$, -1.68 , respectively, as shown in Supplemental Table S2 (https://doi.org/10.3168/jds.2017-13344).

\section{StarchD}

To predict StarchD (Table 4), the candidate model selected using the stepwise method contained the linear effect of HFERM\%DM, starch, DMI\%BW, the effect of location, and interactions between location and dietary factors. The candidate model selected by the backward method contained only the linear effect of DMI\%BW, the effect of location, and interactions between location and dietary factors, and thus was the same as the simplest model. When these 2 candidate models were compared by cross-validation across studies, the model selected using the backward method had the highest $\mathrm{PC}$ (Equation [3], $\mathrm{PC}=0.34, \mathrm{RMSEP}=4.77, \mathrm{CCC}$ $=0.26)$ :

$$
\begin{gathered}
\text { StarchD }=96+0.19 \times \text { HFERM } \% \text { DM }-0.12 \\
\times \text { Starch } \% \text { DM }-1.13 \times \text { DMI } \% \text { BW }
\end{gathered}
$$

where the estimated overall intercept (96), and the overall partial regression coefficients on HFERM\%DM $(0.19)$ and Starch\%DM $(-0.12)$ were weighted by the number of studies from each location. Estimates for intercept and partial regression coefficients for HFERM\%DM and Starch\%DM for Michigan, Ohio, and Georgia were 99, 0.14, and $-0.20 ; 92,-0.028$, and 0.12 ; and $93,0.86,-0.33$, respectively, as shown in Supplemental Table S3 (https://doi.org/10.3168/jds .2017-13344).

\section{DISCUSSION}

To our knowledge, this is the first analysis that used individual observations (instead of treatment means) from several studies to jointly evaluate the effect of diet and animal characteristics on nutrient digestibility. Compared with the use of treatment means, the use of individual observations increase the likelihood of detecting stronger relationships between these variables and better accounts for the variability among the different studies. This has become a common method for combining data sets in human medicine and goes beyond traditional meta-analyses (Stewart and Parmar, 1993; Jones et al., 2009; Riley et al., 2010).

The fact that forage maturity was removed (was deemed statistically irrelevant) during the modeling process was unexpected. However, as our database was composed of studies from different locations and years, the nonassociation between digestibility and forage maturity can be explained by other factors affecting forage digestibility, such as year, field, fertilizer, and environmental conditions. Furthermore, NDF was used as the classification criteria for maturity, and because nfNDF and fNDF were included in the full models these variables may be confounded. The NDF was chosen as the criteria for the maturity classification because better predictors, such as ADF, lignin, and indigestible NDF, were not available in most of the experiments used in this analysis.

An important aspect of our analysis was that the database was composed only of experiments involving lactating cows, with most cows producing 20 to $60 \mathrm{~kg}$ of milk per day; thus, the equations proposed in our study may have limited value for heifers, dry cows, or cows producing outside this range. However, treatment means from studies that evaluated digestibility in dairy heifers at restricted and ad libitum intake (Lascano et al., 2009, 2012; Lascano and Heinrichs, 2011; SuarezMena et al., 2015; Pino and Heinrichs, 2016) were used to test the developed models in dairy heifers, and the predictions were within 1 standard deviation of the reported values. 
Furthermore, the location effect was highly significant for all 3 nutrient digestibilities, with effects on the intercept and partial regressions relationships between digestibility and key predictors. The location effect included factors that were not directly considered in the model, such as growing conditions for forages, environmental conditions for cows, herd genetics and management practices, digestibility markers, and laboratory methods. Thus, because most of the data are from locations in the northern United States (MI and $\mathrm{OH}$ ), our overall equations should be most valuable in similar climates and be used with caution in warmer climates. The results from our study could be used to improve ration balancing, where the coefficients estimated in our equations can be used to adjust a basal digestibility for diet and animal factors.

\section{DMD}

Based on our analysis, DMD decreased 0.83 percentage points for each 1-unit increase in DMI\%BW (Figure 1); however, this coefficient was heterogeneous across the 3 locations (Michigan $=-0.59 \pm 0.22$, Ohio $=-0.18 \pm 0.45$, and Georgia $=-3.22 \pm 0.55$, Supplemental Table S1, https://doi.org/10.3168/jds .2017-13344). For a 650-kg lactating cow, a 1.2-unit change in DMI\%BW is equivalent to 1 multiple of maintenance, so we expect that a 1-unit increase in multiple of maintenance will decrease DMD by $\sim 1.0 \%$. In contrast, the equations proposed by NRC (2001) and Huhtanen et al. (2009) indicate a decrease of 2.4 and $1.9 \%$, respectively (adopting the average values of TDN and OMD at maintenance level in the database of 71 and $67 \%$, respectively; Figure 2). Perhaps our overall model differs from the NRC (2001) because the cows in our data set had greater intakes and were all fed ad libitum. On the other hand, the NRC (2001) digestibility depression equation was based on restricted feeding of animals. Regarding the differences between the proposed equation and Huhtanen et al. (2009), their equation was developed for OM digestibility and the intake was expressed in kilograms per day. Because OM is more digestible than DM, we expected the observed difference. Moreover, using DMI expressed in kilograms per day and not including BW in the model implies the animal intake effect is independent of BW, and this assumption does not work with very different $\mathrm{BW}$, such as Jersey cows with $450 \mathrm{~kg}$ of BW and Holstein cows with $575 \mathrm{~kg}$ of $\mathrm{BW}$.

Unlike the equations of NRC (2001; TDN at production level) and Huhtanen et al. (2009; OM digestibility at production level), our final equation included no direct term for expected digestibility of the diet at maintenance, despite including factors in the initial full model that would be expected to influence basal digestibility (such as percent fNDF, nfNDF, starch, fat, and HFERM\%DM). The fact that our equation did not include any feed factors could be because diets with less digestible nutrients are typically more filling, and thus would be consumed at lower DMI during lactation (Allen, 2000); therefore, it is likely that feed factors that affect DMD and DMI are confounded. This also could explain why the effect of intake on DMD was less in our model; diets with the most digestible nutrients were consumed at higher levels.

The coefficient associated with DMI\%BW $(-0.83)$ has a standard error of 0.20 . Using the average DMI\%BW of $3.5 \%$, the estimated DMD is $66 \%$, with upper and lower 95th percentile confidence interval of 67 and $65 \%$, respectively.

\section{NDFD}

The equation proposed for NDFD has a PC coefficient of 0.53 , the highest $\mathrm{PC}$ coefficient for all equations in our study. The equation proposed for NDFD contains both dietary and intake variables; it contains the linear effects of Grass\%DM and Starch\%DM, and the linear and quadratic effects of DMI\%BW. The intercept and the effect of DMI\%BW were not affected by location; however, the coefficients for Grass\%DM and Starch\%DM were highly heterogeneous across the 3 locations.

The coefficient for Grass\%DM suggests that, for each $1 \%$ increase in grass content of the diet, NDFD increases 0.26 percentage points (Figure 3a); this result is consistent with studies showing that grass has higher NDF digestibility than alfalfa (Smith et al., 1972; Weiss and Shockey, 1991; Kammes and Allen, 2012). The variable Grass\%DM contained 3 grasses sources: wheat straw, orchardgrass silage, and ryegrass silage. The wheat straw was included only in 5 studies and with low levels of inclusions (1.9-5.2\% DM). To verify if the grass source was responsible for the linear increase of NDFD, we deleted the 5 studies containing wheat straw and generated new estimates for the NDFD equation. The Grass\%DM estimates generated containing all the studies or without studies containing wheat straw were very similar (0.26 and 0.27 , respectively), given that the observed effect of grass content is not related with the grasses sources in our study.

Our equation also suggests that for every $1 \%$ increase in diet starch content, NDFD will decrease 0.59 percentage points (Figure 3b); this is consistent with a recent meta-analysis that also found decreased ruminal and total-tract NDF digestibilities as dietary starch is increased (Ferraretto et al., 2013). The depression in NDFD as the level of dietary starch increased is prob- 

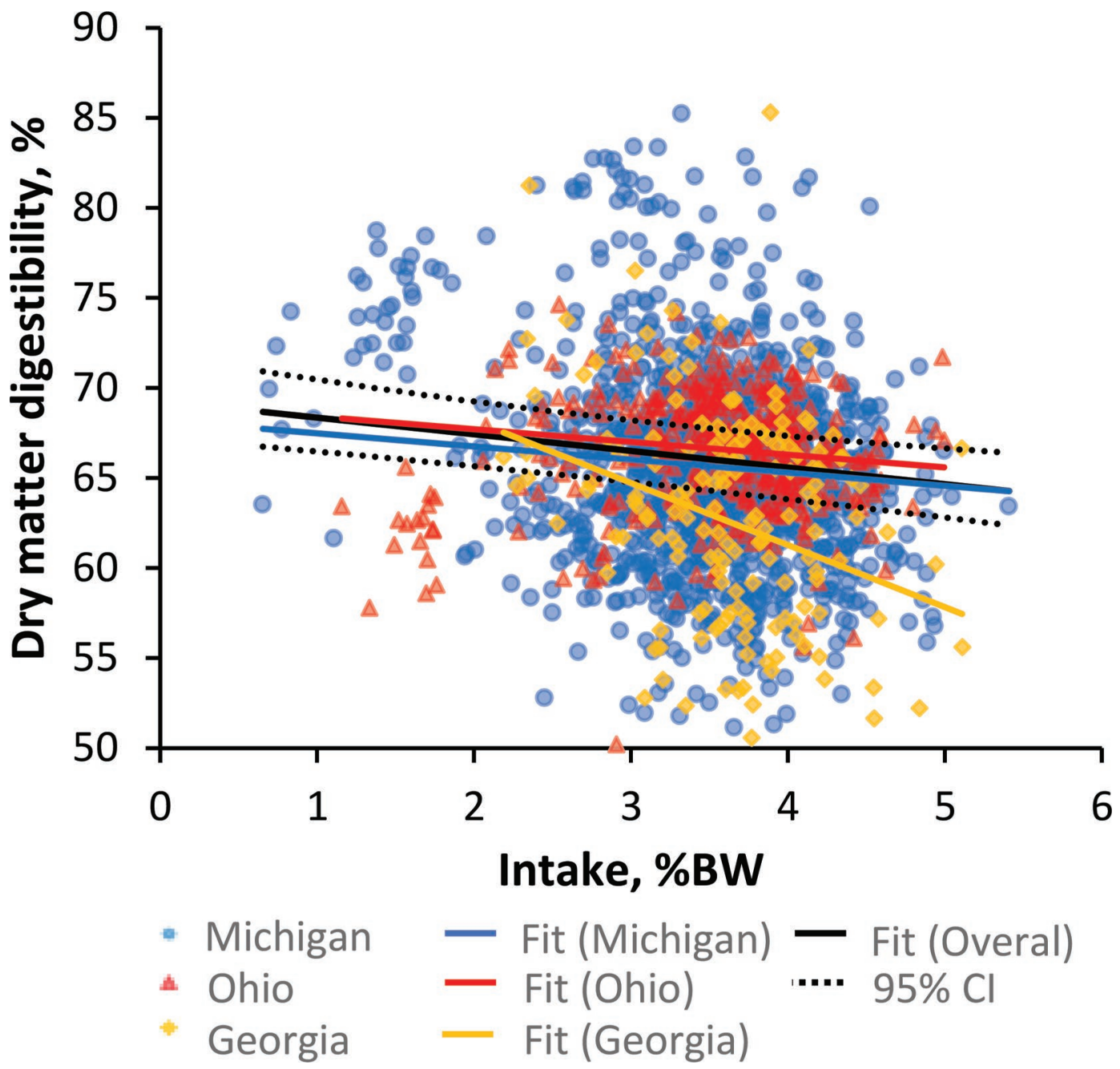

Figure 1. Effect of DMI (expressed as \%BW) on DM digestibility. Each data point represents an individual observation from 1 of the 3 locations included in the analysis (Michigan $=1,362$; Ohio $=416 ;$ Georgia $=164$ ). The estimated overall intercept $(69)$ and estimated overall partial regression coefficient $(-0.83)$ on DMI\% BW were weighted by the number of studies from each location. Estimates for the intercept and partial regression coefficient on DMI\%BW for Michigan, Ohio, and Georgia were 68 and $-0.59,67$, and -0.18 , and 74 and -3.22 . Color version available online.

ably because greater dietary starch content decreases ruminal $\mathrm{pH}$ and thus creates an unfavorable environment for the cellulolytic bacteria (Van Soest, 1994). Based on our model, we predicted that a $20 \%$ starch diet would have $7 \%$ greater NDFD than a $32 \%$ starch diet if all other factors were equal.

Both linear and quadratic terms were significant for intake, with estimates of 3.06 and -0.46 , respectively. These terms show a slight increase in NDFD as intake increased from 1.8 to $3.25 \%$ of BW, followed by decreased NDFD as intake increased further (Figure 3c). The slight decrease in NDFD at very low intakes might be because animals at very low intake were fed low-quality forages. Another possible cause is due to low activity of the microbial population at very low level of intake, so as intake increased the amount of substrate for fermentation increased and so did ruminal microbe activity (Van Soest, 1994). However, the majority of our database was composed of animals eating at moderate to high levels of intake, which precludes conclusions about digestibility at lower levels of intake.

The change from moderate $(2.5 \% \mathrm{BW})$ to high intake $(5.0 \% \mathrm{BW})$ decreased NDFD by only $1.9 \%$. This is in general agreement with a recent meta-analysis that NDFD was not affected by DMI (Ferraretto et al., 2013). In contrast to these results, in a recent metaanalysis, White et al. (2017) reported a greater effect of intake on NDFD and a very little NDFD response to starch. The effect of intake on NDFD in our study was less than the effects of dietary composition (grass and starch content), possibly because level of intake is confounded with forage quality. Within forage type (e.g., 


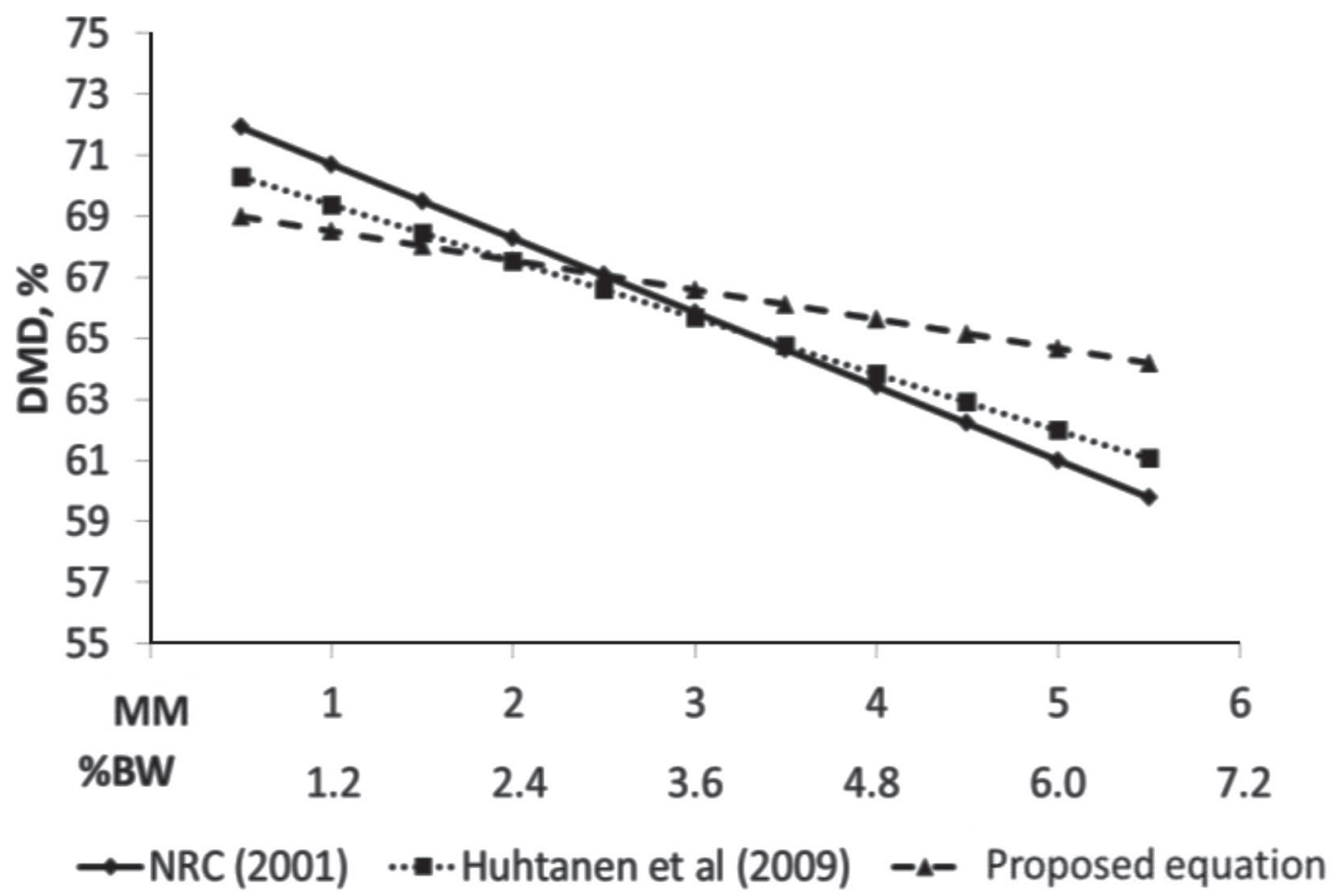

Figure 2. Comparison of the effect of DMI [expressed as multiple of maintenance (MM) or percentage of BW] on DM digestibility estimated by NRC (2001), Huhtanen et al. (2009), and the proposed overall equation (containing the effect of the 3 locations: Michigan, Ohio, and Georgia).

perennial grass, legume), forage NDFD is positively related to DMI, because NDF that digests faster in the rumen also passes faster and is, thus, less filling (Allen, 2000). Therefore, the effect of intake on NDFD might be greater if diets of constant composition were fed at various levels of intake (restricted vs. ad libitum).

Additionally, the literature supports that grasses are more digestible at low intakes, but not at high intakes (Mbwile and Uden, 1997). However, we did not observe an interaction between intake and grass content $(P=$ $0.63)$; the lack of significance for this interaction may be due to a small number of studies with grass in our database.

The coefficients associated with Grass\%DM, Starch\%DM, and DMI\%BW (linear and quadratic; $0.26,-0.59,3.06$, and -0.46 , respectively) had standard errors of $0.041,0.10,1.91$, and 0.27 , respectively. Using the average database values for these variables, the estimated NDFD is $42.5 \%$, with upper and lower 95th percentile confidence intervals of 45.7 and $39.34 \%$, respectively.

One limitation for our NDFD equation was the absence of indigestible and potential digestible NDF (iNDF and pdNDF, respectively) information during the modeling process. The inclusion of iNDF and pdNDF may enhance the prediction of NDFD at production level because they are important NDF fractions related to digestibility. However, of the 54 experiments used in this analysis, only 19 reported iNDF and pdNDF, so we did not use these fractions in the present study.

\section{StarchD}

The best equation for starch digestibility contains both dietary and intake variables. The location affected the intercept, HFERM\%DM, and Starch\%DM, and did not affect the DMI\%BW. Starch digestibility increased 0.19 percentage points for each 1-unit increase in highly fermentable starch (Figure 4a). This effect was expected, as was previously reported (Owens and Zinn, 2005).

Increasing starch content in the diet decreased StarchD by 0.12 percentage points for every $1 \%$ of added starch (Figure 4b), which was due to an increase in starch passage rate or limitation on intestinal starch digestion. Finally, StarchD decreased with greater intakes; a 1-unit increase in DMI\%BW depressed StarchD by 1.13 percentage points (Figure 4c). For example, changing intake from 2.5 to $5 \%$ BW decreased StarchD by 2.6 units.

The coefficients associated with HFERM\%DM, Starch\%DM, and DMI\%BW $(0.19,-0.12$, and -1.13 , respectively) had standard errors of $0.055,0.078$, and 0.14 , respectively. Using the average database values for these variables, the estimated StarchD was $92 \%$, 

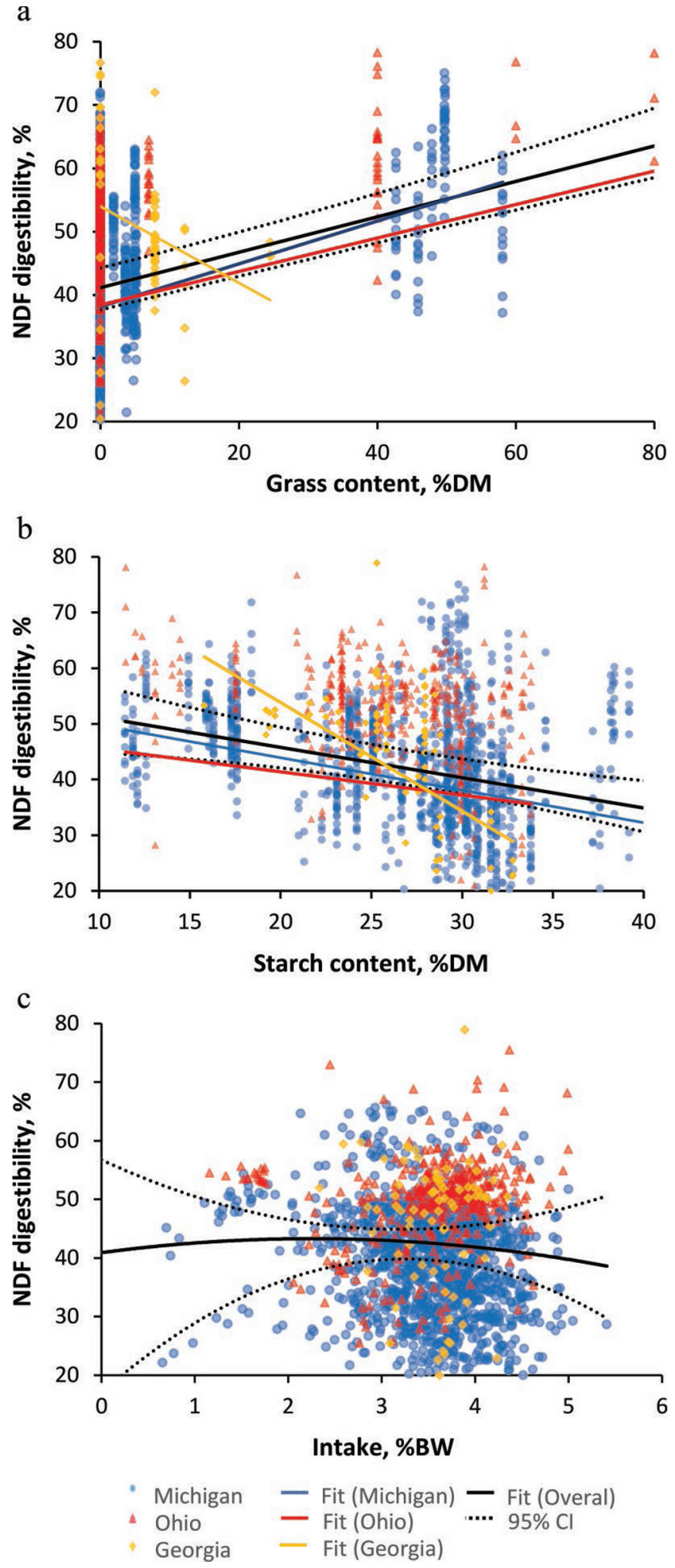

Figure 3. Effect of (a) grass content (expressed as \%DM), (b) dietary starch content (expressed as \%DM), and (c) DMI (expressed as $\% \mathrm{BW}$ ) on NDF digestibility. Each data point represents an individual observation from 1 of the 3 locations included in the analysis (Michigan $=1,352 ;$ Ohio $=416 ;$ Georgia $=164)$. The estimated overall intercept $(53)$ and the overall partial regression coefficients on Grass\%DM $(0.26)$ and Starch\%DM $(-0.59)$ were weighted by the number of studies from each location. Estimates for the intercept and partial regression coefficients on Grass\%DM and Starch\%DM for Michigan, Ohio, and Georgia were 50, 0.38, and -0.60; 45, 0.26, and -0.11 ; and 85, $-0.21,-1.68$, respectively. Color version available online. 
a

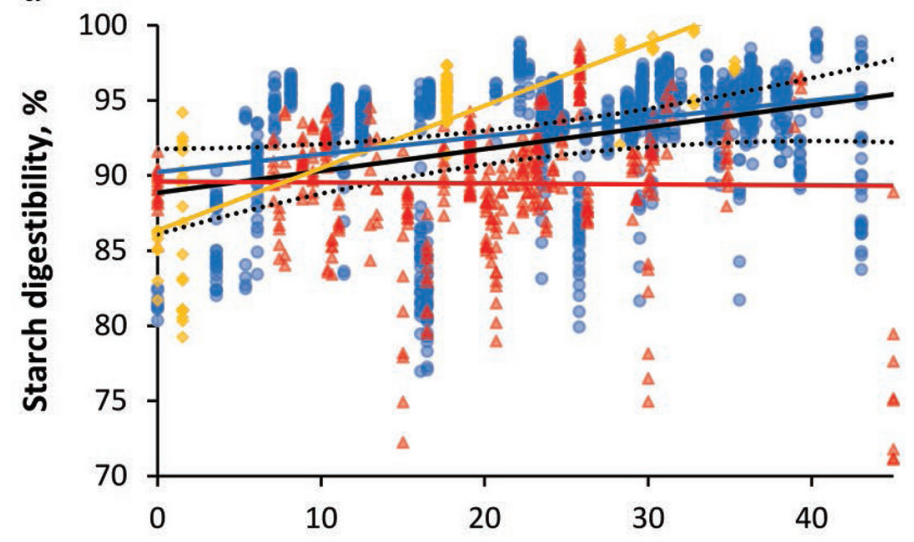

Highly fermentable starch source, \%DM

b

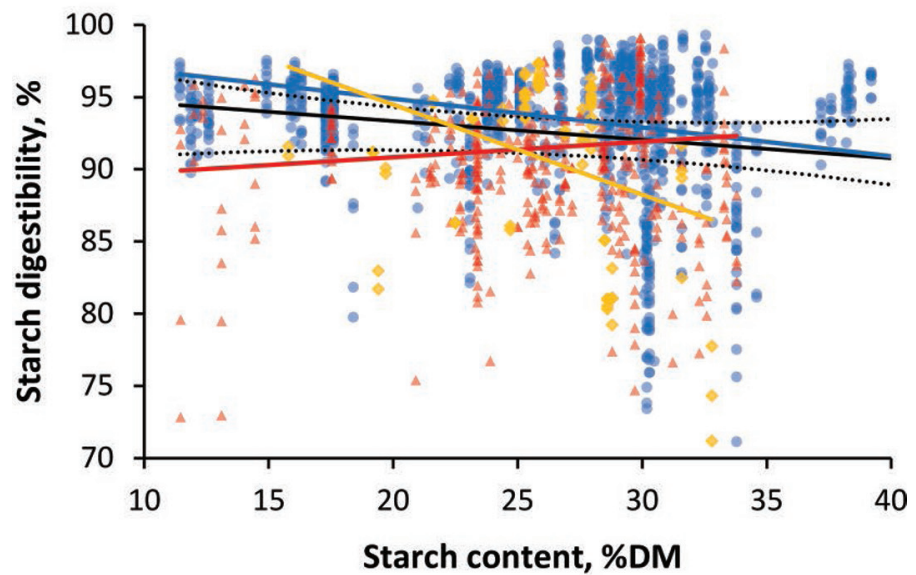

C

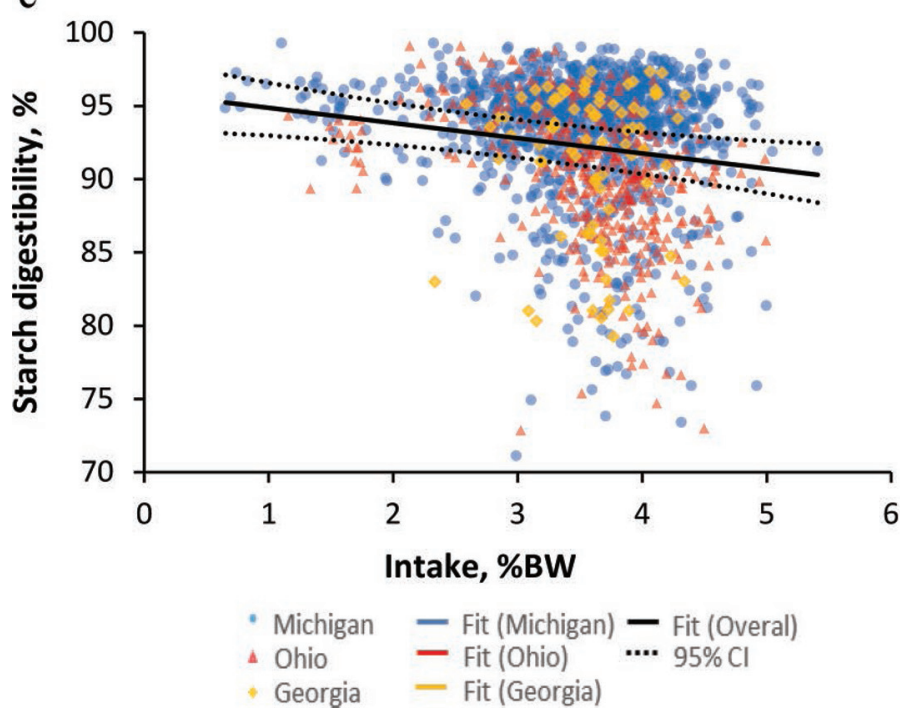

Figure 4. Effect of (a) highly fermentable starch source content (HFERM, expressed as \%DM), (b) dietary starch content (expressed as $\% \mathrm{DM}$ ), and (c) DMI (expressed as \% BW) on starch digestibility. Each data point represents an individual observation from 1 of the 3 locations included in the analysis (Michigan $=1,258$; Ohio $=394$; Georgia $=56$ ). The estimated overall intercept $(96)$, and the overall partial regression coefficients on HFERM\%DM (0.19) and Starch\%DM (-0.12) were weighted by the number of studies from each location. Estimates for intercept and partial regression coefficients for HFERM\%DM and Starch\%DM for Michigan, Ohio, and Georgia were 99, 0.14, and -0.20; 92, -0.028 , and 0.12 ; and $93,0.86,-0.33$, respectively. Color version available online. 
with upper and lower 95th percentile confidence intervals interval of 93 and $91 \%$, respectively.

\section{CONCLUSIONS}

Our results confirm that digestibility is reduced as DMI increased, but at a lower rate than the previous equation used by NRC (2001). The DMD can be predicted based only on the level of intake relative to $\mathrm{BW}$, whereas NDFD and StarchD require diet characteristics in addition to intake to better estimate digestibility. For NDF, increasing grass content increases digestibility and increasing starch content decreases digestibility. For starch, highly fermentable starch sources (high-moisture corn and steam-flaked corn) increase digestibility and increasing starch content decreases digestibility. Additionally, location altered the dietary coefficients (but not the intake coefficients) for NDFD and StarchD, so 1 overall equation for each nutrient digestibility may not work in all locations.

\section{ACKNOWLEDGMENTS}

This project was supported by Agriculture and Food Research Initiative Competitive Grant no. 2011-6800430340 from the USDA National Institute of Food and Agriculture and by Michigan State University AgBioResearch. Rodrigo Araujo de Souza was supported by a $\mathrm{PhD}$ fellowship from National Council for Scientific and Technological Development (CNPq) from the Brazilian Ministry of Education (Brasilia, DF, Brazil).

\section{REFERENCES}

Allen, M. S. 2000. Effects of diet on short-term regulation of feed intake by lactating dairy cattle. J. Dairy Sci. 83:1598-1624.

Cochran, R. C., D. C. Adams, J. D. Wallace, and M. L. Galyean. 1986. Predicting digestibility of different diets with internal markers: Evaluation of four potential markers. J. Anim. Sci. 63:1476-1483.

Colucci, P. E., L. E. Chase, and P. J. Van Soest. 1982. Feed intake, apparent diet digestibility, and rate of particulate passage in dairy cattle. J. Dairy Sci. 65:1445-1456.

Ferraretto, L. F., P. M. Crump, and R. D. Shaver. 2013. Effect of cereal grain type and corn harvest and processing methods on intake, digestion, and milk production by dairy cows through a meta-analysis. J. Dairy Sci. 96:533-550. https://doi.org/10.3168/ jds.2012-5932.

Huhtanen, P., M. Rinne, and J. Nousiainen. 2009. A meta-analysis of feed digestion in dairy cows. 2. The effects of feeding level and diet composition on digestibility. J. Dairy Sci. 92:5031-5042. https:// doi.org/10.3168/jds.2008-1834.

Jones, A. P., R. D. Riley, P. R. Williamson, and A. Whitehead. 2009. Meta-analysis of individual patient data versus aggregate data from longitudinal clinical trials. Clin. Trials 6:16-27. https://doi .org/10.1177/1740774508100984.
Kammes, K. L., and M. S. Allen. 2012. Nutrient demand interacts with forage family to affect digestion responses in dairy cows. J. Dairy Sci. 95:3269-3287. https://doi.org/10.3168/jds.2011-5021.

Kutner, M. H., C. J. Nachtsheim, J. Neter, and W. Li. 2005. Applied Linear Statistical Models. 5th ed. McGraw Hill, Boston, MA.

Lascano, G. J., and A. J. Heinrichs. 2011. Effects of feeding different levels of dietary fiber through the addition of corn stove on nutrient utilization of dairy heifers precision-fed high and low concentrate diets. J. Dairy Sci. 94:3025-3036.

Lascano, G. J., A. J. Heinrichs, and J. M. Tricarico. 2012. Substitution of starch by soluble fiber and Saccharomyces cerevisiae dose response on nutrient digestion and blood metabolites for precisionfed dairy heifers. J. Dairy Sci. 95:3298-3309.

Lascano, G. J., G. I. Zanton, F. X. Suarez-Mena, and A. J. Heinrichs. 2009. Effect of limit feeding high- and low-concentrate diets with Saccharomyces cerevisiae on digestibility and dairy heifer growth and first-lactation performance. J. Dairy Sci. 92:5100-5110.

Mbwile, R. P., and P. Uden. 1997. Effects of age and season on growth and nutritive value of Rhodes grass (Chloris gayana cv. Kunth). Anim. Feed Sci. Technol. 65:87-98.

Nousiainen, J., M. Rinne, and P. Huhtanen. 2009. A meta-analysis of feed digestion in dairy cows. 1 . The effects of forage and concentrate factors on total diet digestibility. J. Dairy Sci. 92:5019-5030. https://doi.org/10.3168/jds.2008-1833.

NRC. 2001. Nutrient Requirements of Dairy Cattle. 7th rev. ed. Natl. Acad. Press, Washington, DC.

Owens, F. N., and R. A. Zinn. 2005. Corn grain for cattle: Influence of processing on site and extent of digestion. Pages 86-112 in Proc. 20th Annual Southwest Nutr. Conf., Phoenix, AZ. Univ. Arizona, Tucson.

Pino, F., and A. J. Heinrichs. 2016. Effect of trace minerals and starch on digestibility and rumen fermentation in diets for dairy heifers. J. Dairy Sci. 99:2797-2810.

Riley, R. D., P. C. Lambert, and G. Abo-Zaid. 2010. Meta-analysis of individual participant data: Rationale, conduct, and reporting. BMJ 340:c221-235.

Smith, L. W., H. I. C. Goering, and C. H. Gordon. 1972. Relationships of forage composition with rates of cell wall digestion and indigestible contents. J. Dairy Sci. 55:1140-1147.

Stewart, L. A., and M. K. B. Parmar. 1993. Meta-analysis of the literature or of individual patient data: Is there a difference? Lancet 341:418-422.

Suarez-Mena, F. X., G. J. Lascano, D. E. Rico, and A. J. Heinrichs. 2015. Effect of forage level and replacing canola meal with dry distillers grains with solubles in precision-fed heifer diets: Digestibility and rumen fermentation. J. Dairy Sci. 98:8054-8065.

Tedeschi, L. O. 2006. Assessment of the adequacy of mathematical models. Agric. Syst. 89:225-247.

Tyrrell, H. F., and P. W. Moe. 1975. Effect of intake on digestive efficiency. J. Dairy Sci. 58:1151-1163.

Van Soest, P. J. 1994. Nutritional Ecology of the Ruminant, 2nd ed. Cornell University Press, Ithaca, NY.

Voelker, J. A., and M. S. Allen. 2003. Pelleted beet pulp substituted for high-moisture corn: 3. Effects on ruminal fermentation, $\mathrm{pH}$, and microbial protein efficiency in lactating dairy cows. J. Dairy Sci. 86:3562-3570.

Weiss, W. P., and W. L. Shockey. 1991. Value of orchardgrass and alfalfa silages fed with varying amounts of concentrates to dairy cows. J. Dairy Sci. 74:1933-1943.

White, R. R., Y. Roman-Garcia, J. L. Firkins, M. J. VandeHaar, L. E. Armentano, W. P. Weiss, T. McGill, R. Garnett, and M. D. Hanigan. 2017. Evaluation of the National Research Council (2001) dairy model and derivation of new prediction equations. 1. Digestibility of fiber, fat, protein, and nonfiber carbohydrate. J. Dairy Sci. 100:3591-3610. https://doi.org/10.3168/jds.2015-10800. 